\title{
EL BIENESTAR SUBJETIVO DE LOS NIÑOS Y ADOLESCENTES CHILENOS. IMPLICANCIAS JURÍDICAS DEL EJERCICIO DE LOS DERECHOS DE NNA: DERECHO A SER OÍDO Y CUIDADO PERSONAL
}

\author{
THE SUBJECTIVE WELL-BEING OF CHILEAN CHILDREN AND ADOLESCENTS. \\ LEGAL IMPLICATIONS OF THE EXERCISE OF THE RIGHTS OF CHILDREN AND \\ ADOLESCENTS: RIGHT TO BE HEARD AND PERSONAL CARE
}

Yasna Elizabeth Otarola Espinoza ${ }^{1}$

\section{RESUMEN}

El artículo indaga sobre la aplicación y efectividad del derecho de los niños a ser oídos y del derecho a ser criados y educados por los padres, crecer en compañía de ambos, en el ordenamiento y en la judicatura chilena, con el objeto de responder preguntas sobre cómo se aplican estos derechos en los tribunales de familia; qué acciones toman los jueces para cumplir adecuadamente con el mandato de la Convención en relación con las materias indicadas y cómo operacionalizan estos derechos en situaciones de dificultad, como es la separación. En ese empeño, se aborda el impacto y la influencia que la dinámica y el funcionamiento de la familia puede tener en el bienestar subjetivo de los niños, niñas y adolescentes; las implicancias y antagonismos que se generan a propósito del ejercicio de los derechos-deberes entre padres e hijos en los casos que involucran el derecho a mantener una relación directa y regular con el progenitor que no tiene el cuidado personal, así como el derecho a ser oído y a que se tenga en cuenta su opinión en instancias judiciales. Además del deber de responder, si se ha dañado el bienestar del hijo, a través de la indemnización correspondiente. Todo lo anterior permite identificar la forma en que los tribunales han resuelto estas implicancias, considerando el bienestar de los NNA chilenos.

Palabras clave: familia; derecho a ser oído, sustracción de menores, bienestar subjetivo y daño.

\begin{abstract}
The article investigates the application and effectiveness of the right of children to be heard and the right to be raised and educated by their parents and growing up in the company of both parents, in the Chilean legal system and judiciary, in order to answer questions about how these rights are applied in the family courts; what actions judges take to adequately comply with the mandate of the Convention in relation to the matters indicated and how they operationalize these rights in difficult situations, such as separation. To that end, we addressed the impact and influence that the dynamics and functioning of the family may have on the subjective wellbeing of children and adolescents; the implications and antagonisms that are generated regarding the exercise of the rights and duties between parents and children in cases involving

\footnotetext{
${ }^{1}$ Abogado, Licenciado en Ciencias Jurídicas y Sociales, por la Universidad de Talca, Chile. Magister en Ciencia Jurídica y Doctor en Derecho, por la Pontificia Universidad Católica de Chile. Especialista en Derecho de Daños y Familia. Actualmente se desempeña como Subdirectora de Doctorado de la Universidad de los Andes, Chile. ORCID: https://orcid.org/0000-0002-6245-3633 E-mail: yotarola@uandes.cl
} 
the right to maintain a direct and regular relationship with the parent who does not have personal care, as well as the right to be heard and to have their opinion taken into account in judicial instances. All of the above makes it possible to identify the way in which the courts have resolved these implications, considering the welfare of Chilean children and adolescents.

Keywords: family; right to be heard; child abduction; child welfare; damage.

\section{INTRODUCCIÓN}

La familia constituye el principal agente de desarrollo socioemocional de los niños, niñas y adolescentes (NNA), pues les transmite valores y normas de conducta, que en el futuro facilitan o impiden su ajuste psicológico y social. La forma de criar y educar que adopten los progenitores con sus hijos influirá significativamente en su desarrollo posterior. De modo que es muy importante que los padres desarrollen competencias parentales que les permitan relacionarse y resolver los conflictos en todas las circunstancias, estén juntos o separados.

En ese contexto, a veces, las familias que se encuentran pasando un proceso de separación o divorcio adoptan decisiones que debilitan la cohesión familiar y que afectan el bienestar de los hijos. De ahí que el desajuste que se produce en los niños tras la separación no deriva de la ruptura, sino del funcionamiento que tiene la familia posteriormente. Algunas de esas decisiones han puesto de relieve la importancia de oír a los NNA efectivamente, saber lo que sienten y piensan. Además de arbitrar medidas en los casos en que uno de los progenitores decida o pretenda desvincular al hijo del otro progenitor, por ejemplo, a través de la sustracción.

Favorablemente, el ordenamiento jurídico chileno y el sistema de administración de justicia chileno han sido objeto de procesos de transformación y modernización. En materia de familia, se han incorporado diversas normas que incluyen el derecho a ser oído y que establecen el derecho de criar y educar a los hijos conforme al interés superior del niño. Sin embargo, el sistema acusa la existencia de ciertas implicancias que plantean diferentes interrogantes relativas a las modalidades en que los tribunales de justicia pueden garantizar estos derechos y, también, la forma en que se interpretan. Uno de ellos es el derecho de los niños a ser oídos y a que su opinión sea debidamente tomada en cuenta en todos los asuntos que puedan afectar su proyecto de vida futura. Otro, el derecho a ser criado y educado por los padres, crecer en compañía de ambos.

Por este motivo, en estas páginas se indaga sobre la aplicación y efectividad de estos derechos en el ordenamiento y en la judicatura chilena, para responder a preguntas sobre cómo 
se aplican estos derechos en los tribunales de familia; qué acciones toman los jueces para cumplir adecuadamente con el mandato de la Convención en relación con las materias indicadas y cómo operacionalizan estos derechos en situaciones de dificultad, como es la separación.

Para ello, se definieron como materias objeto del estudio el impacto y la influencia que la dinámica y el funcionamiento de la familia puede tener en el bienestar subjetivo de los niños, niñas y adolescentes; las implicancias y antagonismos que se generan a propósito del ejercicio de los derechos-deberes entre padres e hijos en los casos que involucran el derecho a mantener una relación directa y regular con el progenitor que no tiene el cuidado personal, así como el derecho a ser oído y a que se tenga en cuenta su opinión en instancias judiciales. Además del deber de responder, si se ha dañado el bienestar del hijo, a través de la indemnización correspondiente.

En el estudio y desarrollo de la investigación se utilizaron diversas fuentes documentales, sentencias de los tribunales superiores de justicia, doctrina chilena y comparada y estudios realizados sobre la base de fuentes primarias, entre otros.

De esta forma, se obtendrá como resultado el estado de las implicancias aludidas y la forma en que los tribunales las han resuelto, considerando el bienestar de los NNA chilenos.

\section{IMPACTO DEL ENTORNO Y DE LAS DINÁMICAS FAMILIARES EN EL DESARROLLO INTEGRAL DEL NNA}

Los cambios de la familia chilena se han dado en un contexto de complejas transformaciones y fenómenos sociales y económicos, entre otros, que han dejado huella en la estructura y conformación de las familias. Desde la incorporación de la madre al trabajo fuera de casa se ha alterado el rol que desempeñaba como única responsable del equilibrio afectivo de los hijos y de su educación y, a su turno, el padre ha pasado a compartir paulatinamente esta labor (GALLEGO, 2012, p. 328). Esta situación ha sido reconocida por las legislaciones, por medio de la igualación de derechos de hombres y mujeres y de las responsabilidades en relación con los hijos. En particular, en cuanto a asumir los derechos y deberes para con los hijos desde la corresponsabilidad y la coparentalidad (ACUÑA, 2013, p. 27; VIVEROS, 2010, p. 1; LATHROP, 2009, p. 213). Sin embargo, al mismo tiempo, se observa una tendencia creciente a la informalidad, transitoriedad y fragilidad de los vínculos matrimoniales y filiales ${ }^{1}$. La formación de uniones consensuadas, la ruptura de parejas y la fecundación extramatrimonial no son una novedad en nuestro país ${ }^{2}$. De modo tal que se ha afianzado la disociación entre 
matrimonio y reproducción; ha aumentado la inestabilidad de las uniones y, como consecuencia, ha surgido la figura del padre ausente, intensificando los riesgos de los hijos.

Así, la familia chilena se ha insertado en una tendencia de cambio a escala global y desde ahí se ha expuesto a los riesgos asociados a esta tendencia. La doctrina advierte de las nuevas fuentes de vulnerabilidad que el cambio en la familia puede provocar, sobre todo en materia de desprotección y disminución de la responsabilidad paterna (PAEZ-MARTÍNEZ, 2016, p. 269; VALDIVIA, 2008, p. 20). Por ello, es importante que la familia asuma las consecuencias que la dinámica y el funcionamiento de ella genera en el desarrollo de los niños $\mathrm{y}$ adolescentes y en el ejercicio de sus derechos.

En ese sentido, se ha considerado que la familia constituye el espacio para la socialización de los hijos; el desarrollo del afecto y la satisfacción de necesidades de todo tipo, sociales, emocionales y económicas, y el primer agente transmisor de normas y valores, debido a que las actitudes, la estabilidad, la seguridad, los modos de ser y el cultivo de las diferentes dimensiones se forman en los primeros años de vida (PALOMAR-LAVER, 2017, p. 90). Por esta razón, incide decididamente en los moldes mentales de los hijos (HERNÁNDEZ, 2005, p. 17), a partir del tejido o entramado de relaciones y vínculos atravesados por la colaboración, intercambio, poder y conflicto entre los miembros de la familia -padre, madre e hijos- al interior de esta (GALLEGO, 2012, p. 333), pues los:

"formatos de pensamiento ego implicativo, esto es, los modos habituales con los que una persona se enfrenta cognoscitiva y afectivamente a la realidad y con los que interpreta y valora su relación con ella son construidos en gran medida por los propios sujetos como consecuencia de sus predisposiciones y experiencias" adquiridas en la familia (HERNÁNDEZ, 1991, p. 405).

Estos "moldes mentales" configuran los pensamientos, sentimientos y las conductas de niños y adolescentes y se adquieren desde:

\begin{abstract}
"el vientre materno, donde se da la máxima simbiosis afectiva y la más drástica independencia al nacer. La familia, donde se reciben cuidados, donde hay expresión cálida de los afectos, donde emerge el 'yo', se ejercita el inicio de la autonomía y del control, y donde se resalta el aprendizaje de lo cotidiano. La escuela y el grupo de amigos, donde se conquista el afecto y se impone un control externo; se practica una autonomía sin respaldos, se incrementa el saber y el dominio sobre la realidad. [...]" (HERNÁNDEZ, 2005, p. 21). Hasta alcanzar el denominado bienestar subjetivo.
\end{abstract}

El bienestar subjetivo de las personas adultas dice relación con la felicidad, la valoración de la vida y con la frecuencia e intensidad de emociones positivas y negativas y se obtiene a través de la satisfacción primaria, la adaptación y la realización (CUADRA y FLORENZANO, 2013, p. 84; GOMEZ et al., 2007, p. 314). La primera sirve de motor para la armonía y la 
realización. La segunda es fundamental para la eficiencia, la felicidad personal y la convivencia. La tercera se hace evidente cuando respetamos las normas y se consigue la autorregulación. Todas ellas interactúan de tal manera que provocan que las personas perciban, reaccionen e interpreten las situaciones que enfrentan de acuerdo con su habilidad emocional, que se manifiesta en la expresión, regulación y el encauzamiento de sus emociones (MOYANO y RAMOS, 2007, p. 180).

En el caso de los niños y adolescentes, la satisfacción con la vida también requiere la inclusión del bienestar subjetivo, igual que en poblaciones adultas (CASAS et al., 2007, p. 7). En ese empeño, los factores psicológicos, psicosociales, sociales y culturales determinan que el tránsito por esta etapa del ciclo vital se realice con mayor o menor éxito. El desarrollo cognitivo, social y afectivo logrado en la etapa de la niñez, las condiciones materiales de existencia, el apoyo familiar y social proveniente de la escuela y otras instituciones de la comunidad desempeñan un rol principal en el bienestar que puede alcanzar el niño o adolescente (CASTELLÁ et al., 2012, p. 274).

De modo que el bienestar no es una cuestión de azar, más bien es la consecuencia de la relación entre el funcionamiento familiar y el niño o adolescente ${ }^{3}$. Tanto es así, que una de las variables que con más seguridad predicen el bienestar subjetivo en este nivel es el estatus familiar. Los niños y adolescentes consiguen mayores niveles de felicidad en ambientes estables $\mathrm{y}$ unidos que les proveen de interacciones significativas y de un nivel de apoyo material y emocional, que generalmente articula positivamente su relación con el medio, según se ha logrado constatar en diversas culturas de inferiores niveles de satisfacción con la vida en adultos que provienen de hogares problemáticos, comparados con los que muestran los que se educaron sin este tipo de dificultades (DÍAZ, 2001, p. 575).

En conclusión, dado el estado de transformación del ambiente que la familia construye y los roles que han asumido sus integrantes en el contexto actual de la sociedad, queda de manifiesto el importante papel que juegan en el bienestar de los niños y adolescentes las instituciones que se enmarcan en su medio particular, como pueden ser la familia y la escuela, por mencionar solo algunas fundamentales en el desarrollo y en el ejercicio de los derechos de niños y adolescentes. 


\section{LA CONVENCIÓN, LA INSTITUCIONALIDAD CHILENA Y EL BIENESTAR DE NIÑOS Y ADOLESCENTES}

A todas estas instituciones se añade el conjunto de normas internacionales que contribuyen a conseguir el bienestar del niño a través del reconocimiento y ejercicio de sus derechos. De modo que el "bienestar" se enmarca, por una parte, en el cumplimiento efectivo de la Convención sobre los Derechos del Niño (CDN) y en la consideración de los niños y niñas como "sujetos de derechos", en tiempo presente y no como resultado de un proceso en donde sus percepciones cuenten "a futuro", cuando sean adultos (OYANEDEL et al., 2015, p. 315). En ese sentido, la noción de bienestar subjetivo apela a principios, tales como la "no discriminación" (artículo 2), al considerar las particularidades y diferencias de los niños según edad, género, etnia, etc. Asimismo, el "interés superior del niño” (artículo 3), al considerarlos sujetos de derechos; la "sobrevivencia y desarrollo", al estimar que debe disfrutar del más alto nivel posible de salud, desarrollarse de forma equilibrada y prepararse para entrar en la edad adulta (artículo 6). Finalmente, el derecho de niños, niñas y adolescentes a "dar su opinión" (artículo 12) en los aspectos que se consideran importantes para su bienestar, según su etapa de desarrollo. También, las reglas que nuestro país ha determinado para otorgar protección integral a niños, niñas y adolescentes, según refrendan las consecuentes adecuaciones y agregaciones en esta materia. En efecto, luego de un largo período de letargo, tras la sanción e incorporación de la CDN a nuestro derecho interno, en los últimos 10 años ha cambiado el Derecho de familia y el Derecho procesal y penal en la parte destinada a la infancia. Por lo tanto, aun cuando persisten obstáculos para hacer efectivas esas transformaciones en la práctica, o bien perduren manejos que restringen la efectividad de los derechos reconocidos a niños, niñas y adolescentes, lo cierto es que la última década se ha caracterizado por una sucesión de importantes transformaciones ${ }^{4}$.

En ese sentido, la reconfiguración de la organización y gestión de los tribunales de familia, al igual que la incorporación de procedimientos más expeditos; la creación de la figura "mi abogado", encargado de representar ante los juzgados competentes -en forma independiente y autónoma de los demás intervinientes en distintos procesos- los derechos e intereses de los niños, niñas y adolescentes; la realización de cursos de especialización en la temática y la instalación de una infraestructura acorde a los nuevos requerimientos constituyen elementos de un sistema de protección en construcción que está logrando asentarse. 
Otra de las transformaciones es la incorporación del derecho del niño a ser oído y que su opinión sea tenida en cuenta. En relativamente pocos años, el escuchar al niño directamente -no a través de un informe técnico o de sus representantes- ha pasado a ser una aplicación que se ha ido extendiendo y formalizando de diferentes maneras (TRONCOSO y PUYOL, 2014, p. 95), pues se ha convertido en un imperativo normativo promovido a través de las decisiones de la Corte Suprema que han acogido favorablemente los recursos de casación interpuestos en aquellos casos en que este "trámite es esencial" (CARRETA, 2018a, p. 420).

2.1 Derecho del NNA a ser oído: implicaciones prácticas de concretización del derecho

El derecho del niño a ser oído y a que su opinión sea debidamente tomada en cuenta en todos los asuntos que lo afectan, en función de su edad y madurez, se encuentra consagrado en el artículo 12 de la CDN. Este artículo establece elementos fundamentales para la comprensión y alcance del derecho: por un lado, la obligación de evaluar la capacidad para formarse un juicio propio y partir de la base de que el niño sí la tiene; por otro, que basta con que comprenda de forma suficiente todos los aspectos para formarse su propio juicio, asignando toda la protección que se requiera para asegurarlo 5 .

En ese contexto, el derecho del niño a ser oído fue consignado tempranamente en la Ley de Menores, en términos de que el juez, en todos los asuntos de que conozca, apreciará la prueba en conciencia y, si fuere posible, deberá oír siempre al menor, cuando lo estimare conveniente ${ }^{6}$, y en la Ley de Adopción en los procedimientos de declaración de susceptibilidad y de adopción propiamente $\operatorname{tal}^{7}$. Posteriormente, fue incorporado en forma expresa en la Ley de Matrimonio Civil, encontrándose consagrado en varios de sus artículos, al regular en los procedimientos de separación judicial, nulidad, matrimonio y divorcio, que cuando existieren menores de edad comprometidos, se debe considerar el interés del niño y oír a aquel que esté en condiciones de formarse su propio juicio en función de su edad y madurez ${ }^{8}$. También, en la Ley de Tribunales de Familia este derecho está consagrado en términos generales como principio, vinculado al rol activo y de protección del derecho a ser oído en todos los procesos que los afecten, y que luego se especifica para todos los procedimientos, generales y especiales ${ }^{9}$. En ese sentido, contempla la comparecencia del niño, niña o adolescente en el marco del procedimiento especial de la aplicación judicial de medidas de protección de los niños, niñas o adolescentes y por consiguiente escucharlo en las audiencias preparatoria, de juicio o en otra especial fijada para tal efecto. Todo lo anterior en un ambiente adecuado, cuidando la integridad física y psíquica del niño, niña o adolescente. Todavía más, podrá hacerlo, personalmente, cuando se encuentre 
vigente una medida de protección judicial o a través de curador ad litem, puesto que la ley provee que "En todos los asuntos de competencia de los juzgados de familia en que aparezcan involucrados intereses de niños, niñas, adolescentes, o incapaces, el juez deberá velar porque éstos se encuentren debidamente representados".

Finalmente, la Ley n. ${ }^{\circ}$ 20.680, que introduce modificaciones al Código Civil, también establece entre los principios generales por los que se rige la responsabilidad parental el derecho del niño a ser oído y a que su opinión sea considerada. Al regularse el régimen y ejercicio del cuidado personal que se confiera a uno de los padres o un tercero, incluye como una de las ponderaciones que tiene que realizar el juez, para la asignación, la necesidad de tener en cuenta "la opinión del hijo"; y el artículo 229, referido a la relación directa y regular, estatuye "su derecho a ser oído" ${ }^{\prime 10}$.

En consecuencia, es indudable que el derecho a escuchar y participar está expresamente reconocido en el ordenamiento legal chileno; sin embargo, en el nivel de las prácticas concretas se presentan situaciones disímiles y se plantean diferentes interrogantes relativas a las modalidades en que los tribunales de justicia pueden garantizar ese derecho y también la forma en que se interpreta. En particular, en los juicios de familia en los que los niños carecen de la calidad de "parte" (la que, en general, es detentada por padres o representantes abogados) ${ }^{11}$, el respeto del derecho de los niños y niñas a ser escuchados y a la debida consideración de su opinión abre la discusión sobre cuestiones vinculadas a las condiciones, modalidades y oportunidad procesal de oír la opinión del niño.

2.1.1 Modalidades en que los tribunales de justicia garantizan el derecho a ser oído

Entre las principales implicancias del derecho a ser oído se encuentra la participación de los niños, niñas y adolescentes en el marco de un proceso judicial, esto es, la forma en que será oído, personalmente o a través de representantes, y si contará con la asistencia y patrocinio de un letrado de su confianza ${ }^{12}$. Además de la edad o en qué condiciones se considera que el NNA es capaz de formarse su propio juicio ${ }^{13}$.

En relación con el primero de los temas, esto es, si será escuchado personalmente o por medio de representantes o a través de un informe elaborado por algún especialista, la práctica evidencia que la participación de los niños - entendida como un proceso permanente- es muy baja, debido a que se reduce a algunas instancias y en rol secundario (VARGAS y CORREA, 2011, p. 188). En ese sentido, el NNA actúa en la audiencia reservada, peritajes e informes diagnósticos, y representado por el curador ad litem. 
Por medio de la primera se pretende recoger la opinión del niño respecto de la situación por la que atraviesa, de forma que el juez pueda considerarla al momento de fallar ${ }^{14}$. Sin embargo, su participación ha resultado insociable, porque es aislada; infructuosa porque no siempre atesora información atingente a la situación del NNA, en términos de indagar sobre sus sentimientos, intereses y expectativas, además de los hechos, y fundamentalmente porque no es posible identificarla en la sentencia, pues no se sabe lo que piensa o dijo y, por consiguiente, si su opinión fue considerada en la resolución y de qué forma (SALUM et al., 2015, p.69).

En segundo lugar, los jueces de familia escuchan a los niños a través de peritajes o informes diagnósticos realizados por profesionales, como los consejeros técnicos. Tales informes se efectúan a solicitud del juez u otra autoridad competente, con el objeto de:

"conocer o apreciar el tipo de vulneración de derechos, su gravedad, cronicidad, efectos en el desarrollo del niño, niña o adolescente y el nivel de vulnerabilidad, así como algunos hechos o circunstancias que podrían estar asociados a la vulneración, constituyéndose en elementos claves de asesoría al juez" ${ }^{15}$ en distintos ámbitos jurídicos.

Conforme sea este informe, a veces se evaluará la existencia y efectos de la vulneración de derechos en el NNA y la ayuda que los rodea; se analizará la credibilidad del testimonio del NNA, el daño sufrido, o se identificarán las necesidades y los recursos que posee a fin de mantener o favorecer su inserción social. Sin embargo, aunque se reconoce su utilidad, existe una confusión en torno a su función, pues se le ha atribuido el "rol de recuperar la voz" del NNA. No obstante, que se trata de un medio de prueba legal elaborado por personas con conocimientos técnicos especiales acerca de los hechos que se discuten, que aportan información apreciada a través de su ciencia o arte (LARRAÍN, 1994, p. 491).

Finalmente, se ha considerado que el curador ad litem permite "recuperar la voz de los niños", debido a que lo representará en el caso de que no tenga uno y en las situaciones en las que los intereses de los NNA son independientes o contradictorios con los de sus representantes. De esta forma, el curador defenderá los derechos personales y procesales de los NNA y para ello debe tener comunicación directa y continua con el NNA, conversar con él; contactar a su entorno más cercano, familia, profesores...; informarle de sus derechos y situación procesal; solicitar audiencias o entrevistas; en síntesis, velar para que sea oído efectivamente ${ }^{16}$. Sin embargo, este representante del NNA es considerado como deficiente en el ejercicio de su labor, porque no cuentan con la preparación suficiente, según refrenda la respuesta inoportuna a traslados efectuados por los tribunales; la falta de una opinión que resguarde el interés superior del niño y que no se encuentran capacitados para ingresar al espacio de observación de sala 
Gesell, dando lugar a la queja de que no defienden a los NNA (GONZÁLEZ, 2017, p. 50). En síntesis, las principales implicancias respecto del curador son la insuficiente formación profesional en temáticas de infancia y adolescencia; vinculación inconstante con el NNA y la inexpresividad de la opinión manifiesta de niños y niñas, en circunstancias de que, de acuerdo a la autonomía progresiva del NNA, debería ser considerada. Todo lo anterior repercute en que los jueces de familia toman decisiones en relación con la vida del NNA sin tener conocimiento de lo que piensa y desea y, por consiguiente, transgrediendo los derechos consagrados en la CDN (BUSTOS, 2018, p. 47).

Ahora bien, respecto de la capacidad del NNA de formarse su propio juicio, como requisito para que sea oído, la Convención sobre los Derechos del Niño establece dos aspectos a considerar como criterio decisivo de su opinión: la madurez y la edad. Respecto de la primera, se ha sostenido que debe evaluarse caso a caso, tomando en cuenta su grado de madurez tanto psíquica como social y cultural. Utilizando como parámetros para la evaluación: la familia, el lugar en que vive (no es lo mismo un niño que crece en la capital que un niño que crece en el campo, lejos de todo desarrollo tecnológico), la educación, el medio en el que se desarrolla y la situación económica. En cambio, en relación con la edad, la Convención omite establecer una, posiblemente debido a las diferencias entre las legislaciones y a que en los tratados internacionales se prefieren las reglas generales, las que serán precisadas por la legislación interna (LLOBET, 2008, p. 213). Sin embargo, igualmente consigna la edad como factor, porque la madurez, en general, se va adquiriendo conforme a esta.

En ese contexto, la mayoría de los ordenamientos jurídicos señala una edad en que es obligatorio, por regla general, escuchar al NNA, que va desde los 12 a los 14 años. Además, establecen que debe oírse al menor en los casos en que la decisión le afecte ${ }^{17}$. A modo de ejemplo, Chile ha prescrito expresamente que en materia de adopción:

"[...], el juez tendrá debidamente en cuenta las opiniones del menor, en función de su edad y madurez", con el carácter de decisiva, pues en caso de negarse (el agregado es mío "[...] el juez dejará constancia de las razones que invoque el menor. Excepcionalmente, por motivos sustentados en el interés superior de aquél, podrá resolver fundadamente que prosiga el respectivo procedimiento" ${ }^{18}$.

Esta disposición y todas aquellas que hacen alusión a la edad y madurez debieran ser relacionadas con el artículo 16 de la Ley de Tribunales de Familia y con el artículo 12 de la CDN e interpretadas conforme a la idea de que el NNA que esté en condiciones de formarse un juicio propio debe ser evaluado desde la regla general de que tiene capacidad para formarse sus propias opiniones y reconocer que tiene derecho a expresarlas; no correspondiendo al niño, niña 
o adolescente probar que tiene esa capacidad. En atención a ello, la regla general es que los jueces deben escuchar al menor, independientemente de su edad. De modo que tiene el deber de escuchar al NNA "en todos los asuntos que afectan al niño", como se desprende de las normas citadas anteriormente y en especial del artículo 12 de la $\mathrm{CDN}$; pero solo tomará en cuenta dicha opinión en función de su edad y madurez; o sea, para evaluar la opinión del menor puede distinguir, conforme su edad, entre niños y adolescentes (VARGAS y CORREA, 2011, p. 194). En consecuencia, puede tomar o excluir la opinión, y en este último caso podrá hacerlo si el NNA no está en condiciones de formarse un juicio propio, sea inconveniente para el niño o no pueda expresarse de forma alguna, según se deduce del hecho de que cuando

\footnotetext{
"existieren menores de edad comprometidos, el juez deberá considerar especialmente el interés superior del niño, y oirá a aquel que esté en condiciones de formarse un juicio propio, teniéndose debidamente en cuenta sus opiniones en función de la edad y madurez, al resolver todos los asuntos relacionados con su persona o sus bienes" (BARCIA, 2013, p. 37).
}

Por último, no importando la edad -según se ha visto-, igualmente resulta necesario reconocer formas no verbales de comunicación, como el juego, la expresión corporal y facial y el dibujo y la pintura, mediante los cuales los niños muy pequeños demuestran esta capacidad de comprender (ROBLEDO, 2017, p. 48; CARRETA, 2018b, p. 105), debido a que siempre debe ser oído, aunque para considerar su opinión habrá que estarse a si tiene juicio propio, cuestión que se realiza mediante un examen caso por caso (LANSDOWN, 2005, pp. 49-50).

En conclusión, el ejercicio del derecho a ser oído demanda superar y mejorar las implicancias de no escucharlo, la forma en que se hace y la participación. Ello requiere de un mayor y profundo análisis sobre las condiciones del sistema, la competencia y formación de los operadores, a fin de facilitar el acceso de los niños a ver satisfecho su derecho y que este no se torne solamente en la obligación de ser escuchados en una audiencia con el juez. También, exige incorporar en la decisión de este las razones por las cuales consideró o no su opinión, habiendo evaluado si podía formarse un juicio.

\section{DERECHO DEL NNA A MANTENER UNA RELACIÓN DIRECTA Y REGULAR CON EL PROGENITOR QUE NO TIENE EL CUIDADO PERSONAL}

Como consecuencia de la filiación, nace entre padres e hijos una serie de deberes y derechos. Entre ellos se encuentran todos aquellos que permiten relacionarse, comunicarse y vivir juntos con los hijos. Se trata de deberes paterno-filiales que se concretan día a día, tanto 
en aspectos patrimoniales como extrapatrimoniales y que se basan, por una parte, en la obligación de los padres de procurar su mayor realización espiritual y material posible; por otra, en que los hijos deben respeto y obediencia a sus padres. Cuando los padres viven juntos la participación resulta o debiera ser comúnmente activa, equitativa y permanente. Sin embargo, el rompimiento de los padres, casados o no, impide que convivan ambos con los hijos, incluso si se acuerda el cuidado personal compartido.

De modo que si los padres se encuentran separados, a ambos corresponde cumplir con estos deberes y ejercer sus derechos, sea que se atribuya el cuidado personal del hijo a uno de los padres y al otro la relación directa y regular. Así lo establece la Ley n. ${ }^{\circ} 20.680$ :

\begin{abstract}
"Sea que se decrete judicialmente el régimen de relación directa y regular o en la aprobación de acuerdos de los padres en estas materias, el juez deberá asegurar la mayor participación y corresponsabilidad de éstos en la vida del hijo, estableciendo las condiciones que fomenten una relación sana y cercana" ${ }^{19}$.
\end{abstract}

Con lo cual, el progenitor que no tiene el cuidado de los hijos comparte la corresponsabilidad de criar y educarlos.

El ordenamiento chileno regula esta materia en el art. 224 del CC, el cual dispone que corresponde a los padres, o al padre o madre sobreviviente, el cuidado personal de la crianza y educación de los hijos. Por su parte, el art. 225 del mismo cuerpo legal agrega que, en caso de que los padres vivan separados, podrán determinar de común acuerdo que el cuidado personal de los hijos corresponda al padre o a ambos en forma compartida. Se establece, ahí mismo, que, a falta de acuerdo, los hijos continuarán bajo el cuidado personal del padre o madre con quien estén conviviendo. Es decir, el Derecho chileno contempla la posibilidad de acordar el cuidado personal en uno de los padres o compartirlo en el caso de que se hayan separado. No obstante, si el juez atribuye el cuidado personal del hijo a uno de los padres, la ley sí reconoce y garantiza que aquel niño cuyos padres se encuentran separados mantendrá contacto directo y regular con aquel de los padres con quien no viva, considerando el interés superior y se cumplan los criterios establecidos en el art. 229 del Código Civil. Por tanto, la ley distingue claramente el cuidado personal del régimen de relación directa y regular. Mientras el primero supone ejercer la crianza y la educación del hijo, el segundo se entiende como el derecho del hijo a mantener un contacto regular con su padre o madre con el cual no convive.

Sin embargo, el establecimiento de este régimen de relación entre padres e hijos: individuales de los adultos, normalmente en conflicto, y descuide el desarrollo integral del menor en quien debe residir la preocupación fundamental, principalmente en casos de crisis matrimonial" (ACUÑA, 2013, p. 22). 
En ese sentido, no hay reglas que determinen cuáles son los aspectos o decisiones en las que puede y debe intervenir el padre o madre no custodio. La doctrina ha intentado dar respuesta desde la coparentalidad, pues permite la cooperación entre los padres y la mantención de una relación de apoyo mutuo centrado fundamentalmente en la crianza de los hijos, estando ambos implicados activamente en las vidas de estos (FARIÑA et al., 2017, p. 296). La coparentalidad, por tanto, supone la decisión de seguir decidiendo, la disponibilidad para hacerlo y la predisposición para actuar individualmente ante los hijos manteniendo la coherencia de los criterios comunes; es más que un reparto de tareas (BOLAÑOS, 2015, p. 61), aunque en la realidad, muchas veces sea así.

En este último caso, tras la separación, a veces la situación se agrava, si de ella resulta que solo uno participa y toma decisiones unilaterales sobre aspectos trascendentes de la vida del NNA. Por ejemplo, sobre cuál será el lugar de residencia, y en ese empeño engaña al padre no custodio a través de una solicitud de autorización para salir del país por un determinado tiempo, siendo la verdadera intención quedarse definitivamente en este.

\subsection{SALIDA DEL NIÑO AL EXTRANJERO}

El ejemplo anterior pone en evidencia una situación cada vez más frecuente, si los padres tienen diferentes nacionalidades o teniendo la misma, uno de ellos desea fijar la residencia del hijo en un lugar distinto al que vive el otro, tras la separación. La ley contempla expresamente una norma que limita las facultades de aquel de los padres que mantiene el referido cuidado, en lo tocante a la determinación del lugar de residencia. Así, el artículo 49 de la Ley n. ${ }^{\circ} 16.618$, que regula la salida de menores desde el territorio nacional, dispone que:

\footnotetext{
"si la tuición del hijo no ha sido confiada por el juez a alguno de sus padres ni a un tercero, aquél no podrá salir sin la autorización de ambos padres, o de aquel que lo hubiere reconocido, en su caso".
}

Asimismo, establece que en caso de que el cuidado personal haya sido confiado a uno de los padres o a un tercero, el hijo no podrá salir del territorio nacional sin la autorización de aquel a quien se le hubiere otorgado ${ }^{20}$. Por último, también se requerirá la autorización del padre o madre no custodio a favor de quien se haya regulado un régimen de relación directa y regular con el hijo. El padre o madre que otorga la autorización no tiene limitación en la forma de otorgarla, puede ser por un tiempo determinado, o bien indefinido. 
Ahora bien, en el caso de que se acredite que dicha autorización no pudo otorgarse o que ha sido denegada sin motivo plausible por quien deba prestarla, podrá ser otorgada por el juez $^{21}$, considerando el beneficio que le pudiese reportar al hijo dicho viaje, y debiendo siempre señalarse por el tiempo que se concede dicha autorización ${ }^{22}$. De modo que, de acuerdo con la ley, el juez no debe otorgar autorización para radicarse indefinidamente en el extranjero (ETCHEBERRY, 2019, p. 4), decisión que se ha seguido regularmente en la práctica judicial, basada fundamentalmente en que no es beneficioso para el NNA y que el padre o madre no custodio perderá la relación directa y regular ${ }^{23}$.

Sin embargo, en ocasiones, la Corte Suprema ha dado lugar a estas autorizaciones si se ha logrado acreditar que el viaje es ventajoso para el hijo, que no perderá el vínculo con el otro padre y que se consideró su interés superior. Así, por ejemplo, en un caso, la madre solicitó autorización para radicarse con el hijo definitivamente en México. La Corte accedió y estableció un régimen de relación directa y regular con su padre ${ }^{24}$. En otro, la madre pidió autorización para viajar con su hija a Francia y radicarse ahí durante un año. La Corte Suprema confirma la autorización y enmienda la decisión de la Corte de Apelaciones solo en la parte de arbitrar los medios para que se mantenga el régimen de relación directa y regular con el otro padre ${ }^{25}$. Asimismo, en otra causa, la madre pidió autorización para salir del país con sus dos hijos con el objeto de radicarse en Estados Unidos; la Corte Suprema autorizó porque consideró que la madre que tenía el cuidado personal podía decidir el lugar de residencia y que era beneficioso para los hijos ${ }^{26}$. En otro caso, la madre solicitó autorización para radicarse de forma definitiva en Montreal, o bien durante el término de cuatro años, la Corte Suprema accede a la petición, basada en el hecho de que la determinación se ajusta a lo que aparece como beneficioso para el menor, y no solo cede a favor de los intereses de su madre, en cuanto posibilita que el hijo se reencuentre con su familia materna, país y cultura de origen, sin perjuicio de que la autorización de que se trata no es definitiva, sino por un período determinado, y que la vinculación con el padre no puede ser desconocida o suprimida ${ }^{27}$. Todavía más, el Tribunal Constitucional ha conocido de requerimientos de inaplicabilidad por inconstitucionalidad presentados respecto del artículo 49 de la Ley n. ${ }^{\circ}$ 16.618, en procesos sobre autorización de salida del país, debido a que el juez modificó tácitamente el régimen de relación directa y regular al autorizar la salida del menor del país, rompiendo así el vínculo paterno-filial ${ }^{28}$.

En consecuencia, estas decisiones demuestran la importancia que adquiere en este contexto el principio del interés superior del niño, en virtud de que las medidas están basadas en esta consideración y que se ha tomado la precaución de mantener periódicamente, salvo en 
circunstancias excepcionales, relaciones personales y contactos directos con el padre no custodio.

Complementariamente, el legislador adiciona algunas situaciones particulares. La primera consiste en otorgar la autorización para salir del país con el NNA en distintas ocasiones por el término de hasta dos años a la persona que tiene el cuidado personal, siempre que se acredite que el otro progenitor, injustificadamente, ha dejado de cumplir el deber, regulado judicial o convencionalmente, de mantener una relación directa y regular con su hijo. El plazo de permanencia del menor de edad en el extranjero no podrá ser superior a 15 días en cada ocasión $^{29}$. Así ocurrió en el caso de una madre que tenía el cuidado personal y solicitó salir del país con sus hijos sin destino definido, por un período no superior a 20 días; la Corte Suprema accedió a la petición, no obstante que el padre no custodio cumple con la relación directa y regular $^{30}$.

La segunda está contemplada en el artículo 19 de la Ley $n .^{\circ} 14.908$, que establece que se privará al padre o madre alimentante de autorizar la salida del país de sus hijos menores de edad si constare que en el proceso en contra del alimentante se hubiere decretado dos veces alguno de los apremios señalados en los artículos 14 y 16. En este caso, el tribunal autorizará la salida del país de los hijos menores de edad sin necesidad del consentimiento del alimentante $[\ldots]$.

La tercera permite la suspensión del derecho de alimentos si el NNA permanece en el extranjero, transcurrido el plazo que el juez había determinado, sin causa que lo justifique. Eventualmente, también podrá solicitarse la restitución del menor en virtud de lo establecido en el Convenio sobre los Aspectos Civiles de la Sustracción Internacional de Menores ${ }^{31}$. Por último, el juez de familia puede prohibir la salida de un menor de edad del país, como medida cautelar en procedimiento proteccional ${ }^{32}$, en cualquier momento del procedimiento, y aun antes de su inicio, de oficio, a solicitud de la autoridad pública o de cualquier persona, cuando sea necesario para proteger los derechos del niño, niña o adolescente.

En conclusión, las autorizaciones para salir del país cuando existe un régimen relacional asimétrico entre los padres ponen a prueba la definición del vínculo parental, en la que los padres deciden qué tipo de relación quieren mantener a partir de la decisión de uno de ellos sobre la residencia de los hijos en el extranjero. En las situaciones en que los padres no han logrado hacerlo, los tribunales de justicia han intentado encontrar una nueva manera de relacionarse que garantice la continuidad de su función común, asegurando el interés superior 
del niño y el derecho a relacionarse con ambos padres, a fin de obtener el mejor bienestar posible.

\subsection{SUSTRACCIÓN DE MENORES Y SECUESTRO}

Otra de las inconsistencias que en ocasiones acompaña el ejercicio de los derechos del niño, en particular, el derecho a crecer en compañía de ambos padres, es la sustracción o secuestro de menores ${ }^{33}$. Estas situaciones ilícitas se han generado por el fracaso de la coparentalidad cooperativa y complementaria entre progenitores, especialmente en familias binucleares o de parentesco extenso, o multiculturales, con diferencias étnicas o religiosas (RODRIGUEZ et al., 2015, p. 47). Informes recientes han evidenciado que la sustracción parental se ha convertido en un problema mundial, entre cuyas causas destacan divorcios de matrimonios mixtos, nacionalismo judicial, abuso de los derechos de visita y el maltrato infantil ${ }^{34}$.

En Chile, según estadísticas del Ministerio Publico, se registró un total de 1.503 ingresos asociados al delito de sustracción de menores (artículo 142 del Código Penal), en el período comprendido entre diciembre de 2000 y enero de 2015. Estos datos demuestran, que los NNA pueden ser limitados en su libertad cuando su padre o su madre, de manera discrecional, decide impedir su convivencia con el otro progenitor. En estos casos, el reconocimiento a la violación de los derechos del niño y de la niña, y a los del padre o madre privado del cuidado personal, se circunscribe a que el acto pueda encuadrarse en el delito sustracción que se configura como tal si se trata de un menor de 18 años:

\footnotetext{
"Aunque respecto de los mayores de 10 años, pero menores de 18 años, la ley reconoce un germen de libertad de autodeterminación, según se infiere de la interpretación de los artículos 142 y 357 del Código Penal Chileno". (GUERRERO, 2017, p. 111).
}

Haciendo relevante para la conformación del tipo la falta de consentimiento del menor de edad, que ha sido afectado en su seguridad como presupuesto de su libertad ambulatoria (MATUS y RAMIREZ, 2014, p. 251).

Así, en el ámbito de la familia el delito se comete -en principio- si el progenitor que no ostenta el derecho de cuidado personal sustrae a uno o a alguno de sus hijos menores, trasladándolos fuera del lugar de su residencia habitual con la finalidad de impedir la restitución del menor a su domicilio o la relación con el otro. También, si teniendo el cuidado personal decide llevarse al NNA con el objetivo de separarlo del otro progenitor. Sin embargo, la 
jurisprudencia de los tribunales chilenos ha vacilado respecto de considerar a los progenitores como sujetos activos del delito, debido a que ha seguido la tesis de que el sujeto activo puede ser cualquiera, menos quien tenga a su cargo la seguridad del menor dentro de un determinado espacio perimetral, esto es:

"una esfera o ámbito jurídico establecido para su convivencia, ya sea de manera legal -producto del matrimonio de sus padres-, ya sea convencional -producto de un acuerdo completo y suficiente en caso de crisis familiar y divorcio- o de manera judicial, a través de una resolución emitida por un tribunal de familia" (GUERRERO, 2017, p. 110).

También, porque no se afectan los derechos tutelares si la persona que lo toma está a cargo del NNA y que no obsta al cumplimiento del Convenio de La Haya sobre los Aspectos Civiles de la Sustracción Internacional de Menores; ya que su propósito no es penalizar el traslado lícito de menores de un Estado a otro, sino asegurar el ejercicio de los derechos conferidos a los padres en el ámbito civil. De modo que, excepcionalmente, considera que los padres del menor pueden ser sujetos activos siempre ${ }^{35}$; la mayoría de las veces ha estimado que los progenitores podrán serlo según las circunstancias del caso ${ }^{36}$.

Lo recién descrito significa, por una parte, que el delito de sustracción existe cuando hay una resolución judicial sobre el cuidado personal del NNA. De manera que no aplica en los casos en que no se ha establecido por un juez cuál progenitor tendrá el cuidado, ya que, por ley, si están juntos, ambos tendrían igual derecho, y también en aquellos en que la sustracción la realiza quien ostenta el cuidado personal. Por otra, que procede si las circunstancias o factores que rodean el caso lo ameritan, sin regirse por una regla general sobre el ejercicio legítimo del cuidado personal o la relación directa y regular. En ese sentido, se consideró que los antecedentes que obraban en la causa eran suficientes para justificar la existencia del delito investigado, como las sospechas de participación de los requeridos en este; lo que esencialmente se funda en la resolución adoptada de 16 de marzo de 2018 por el juez de familia, que concedió el cuidado personal de los niños, de cuatro y tres años a la época, a sus abuelos maternos, disponiendo también que sus padres, esto es, los imputados, los entregaran en el plazo de 24 horas, además de suspender el derecho a relación directa y regular de los progenitores, resolución que no fue cumplida, ya que conforme el mérito de los antecedentes reunidos, a fines de marzo de 2018, los imputados salieron del país por paso no habilitado, llevando consigo a ambos menores ${ }^{37}$. En otro caso, en cambio, se señaló que de los antecedentes aparece de manifiesto que entre el querellante y la querellada, en el marco de un proceso de autorización de salida del país tramitado respecto de la niña -hija en común de ambos- ante el Segundo Juzgado de Familia de Santiago, se celebró una transacción en la que el recurrente autorizó a la 
madre para sacar a la menor del país entre ciertas y determinadas fechas, de lo que se colige que su salida del país lo fue con expresa autorización de su padre, circunstancia que permite descartar de plano la existencia del ilícito de sustracción de menores atribuido a los querellados ${ }^{38}$.

En conclusión, los tribunales chilenos han admitido pronunciamientos dispares sobre la base de las circunstancias de cada caso, privilegiando a veces los derechos tutelares otorgados, o bien considerando las razones por las cuales el progenitor llevó a cabo el delito de sustracción de menores.

\subsection{CONVENIO DE LA HAYA DE 1980 SOBRE ASPECTOS CIVILES DEL SECUESTRO INTERNACIONAL}

En este ámbito, ha resultado fundamental considerar que Chile se encuentra adherido al Convenio de La Haya sobre los Aspectos Civiles de la Sustracción Internacional de Menores desde 1980. El Convenio tiene por objeto la restitución inmediata del menor al Estado de la residencia habitual, de acuerdo al principio del interés superior del niño ${ }^{39}$, según expresa en su preámbulo.

Por consiguiente, la finalidad del Convenio es el mantenimiento del statu quo anterior a la sustracción, puesto que prioriza la restitución del menor y el mantenimiento de la vigencia y eficacia de los derechos tutelares establecidos legal o convencionalmente en el país de residencia habitual, sin cuestionar o entrar a estudiar a quién corresponde el cuidado del NNA. Se aplica a los desplazamientos de niños, menores de 16 años, que se encontraban bajo cuidado por resolución judicial dictada con anterioridad al traslado o después de que este se produjo. Aunque requiere como condición que se haya estado ejerciendo efectivamente el derecho de tutela al momento del traslado o que dicho derecho no se pudo ejercer.

El Estado parte se compromete a restituir al NNA de forma inmediata, en el transcurso de un año. En el caso de que hubiere transcurrido más de un año desde la retención, la restitución solo se efectuará si no se hubiera integrado a la nueva residencia habitual, con idénticas exigencias del supuesto anterior. Salvo que se demuestre que la persona que se hacía cargo del menor no ejercía de modo efectivo el derecho de custodia, traslado o había consentido o posteriormente aceptado el traslado; que exista un grave riesgo de que la restitución del menor lo exponga a un peligro grave físico o psíquico o que el menor se oponga a la restitución. 
Con todo, en estos casos, la parte afectada podrá solicitar en el Estado al que fue trasladado el niño el reconocimiento y ejecución de la resolución del derecho de tutela, sea cual fuere, otorgado en el Estado donde residía el menor con anterioridad al traslado ${ }^{40}$. También, puede requerir directamente la restitución del menor ante la autoridad competente del Estado en que se encuentra el menor con posterioridad al traslado. Por último, iniciar un procedimiento sobre medidas de protección de menores en el Estado al que ha sido trasladado.

Todas estas medidas permiten de alguna manera, unas más y otras menos, restablecer la situación existente con anterioridad a la sustracción, evitando que el sustractor consiga su fin mediante la alteración de la residencia habitual cuando se produce una sustracción de menores y la prohibición que existe de que el Estado de refugio legalice la situación pronunciándose sobre a quién corresponde la tuición.

En ese sentido, los tribunales de justicia chilenos, aunque reconocen en sus decisiones el valor del Convenio y su finalidad, en cuanto garantiza la restitución inmediata de los menores trasladados o retenidos de manera ilícita en cualquier Estado contratante y vela porque los derechos de custodia y de visita vigentes en uno de estos se respeten en los demás ${ }^{41}$; en general, no acceden a las restituciones ${ }^{42}$.

Así, por ejemplo, la Corte Suprema enmienda la decisión de la Corte de Apelaciones porque estima que los jueces incurrieron en errónea aplicación e interpretación del artículo 13 letra b) del Convenio sobre los Aspectos Civiles de la Sustracción Internacional de Menores, al no considerar la posibilidad de que la menor sea trasladada a su país de origen, ya que representa un evento cierto de que sea separada de su madre, lo que constituye un riesgo efectivo e inminente de que el desarrollo de la menor se vea afectado o expuesto a una situación intolerable ${ }^{43}$. En el mismo sentido, sostiene que los hechos establecidos permiten arribar a la conclusión de que ordenar el regreso de la menor a Noruega importaría infligirle un grave daño, ya que con ello se la extrae de un medio al cual se encuentra integrada; en el hecho, se la priva de la presencia y cuidados de su madre, pues tendría que incorporarse a una sociedad que culturalmente es muy diferente a la idiosincrasia de la sociedad chilena y latina. En tal caso, es misión del derecho velar por el interés superior de la menor, porque -como ya lo había consignado el Excelentísimo Tribunal en una sentencia de 1956, citada en otra de la Corte de Apelaciones de Valparaíso de 3 de junio de 1998-:

"en materia de menores es necesario adoptar disposiciones anticipadas o de prevención que conduzcan al logro de un fin esencial, que no es otro que el ulterior bienestar del niño" 44 . 
Como se puede apreciar, las decisiones acordadas se ajustan a las tres causales que permiten denegar el traslado al lugar habitual de residencia; en particular, privilegian el bienestar del NNA conforme al interés superior del niño. Todavía más, son respetuosas de la obligación de abstenerse de emitir pronunciamientos acerca del fondo del asunto y se limitan a cumplir con ejecutar lo resuelto, aunque el retorno no es la regla general, sino las excepciones dispuestas en el Convenio.

\section{ALGUNAS PALABRAS SOBRE EL DAÑO OCASIONADO POR LA PRIVACIÓN DE LA COMPAÑÍA DE UNO DE LOS PROGENITORES}

La privación de la compañía o la obstaculización de la relación del NNA con uno de sus progenitores puede lesionar tanto al progenitor que tiene el cuidado personal como al que tiene la relación directa y regular y, desde luego, al niño. En efecto, cualquiera de ellos puede verse privado de la compañía del hijo, generándose daño moral o extrapatrimonial.

En el derecho comparado, tal conducta ha sido catalogada como un ataque al derecho al respeto de la vida familiar, reconocido en el artículo 8 del Convenio Europeo de Derechos Humanos (CEDH), y dado lugar a compensaciones en algunos $\operatorname{casos}^{45}$, debido a que se ha considerado que la relación personal entre un progenitor y su hijo constituye un elemento fundamental de la vida familiar, aunque haya cesado la convivencia entre los padres, razón por la que no puede ser obstaculizada por ninguna persona.

En este contexto, ha resultado emblemático el fallo español de 20 de junio de 2009 que aplica el régimen de responsabilidad extracontractual en un caso de obstaculización de las relaciones paterno-filiales. La sentencia condena a una madre al pago de 60.000 euros por apartar a su hijo del padre titular de la custodia durante 11 años, como consecuencia de su traslado con el menor a Estados Unidos. La madre viajó con el niño a dicho país sin regresar a España. Tras el archivo de las actuaciones penales, se atribuyó al padre la guarda y custodia del menor por el riesgo que suponía la convivencia con la madre. El padre intentó sin éxito la ejecución de la sentencia en los Estados Unidos y luego demandó a la madre de indemnización. El Tribunal Supremo acogió la acción, basado en el artículo 1902 CC y en la jurisprudencia del Tribunal Europeo de Derechos Humanos (TEDH) sobre el derecho a la vida familiar consagrado en el artículo 8 del CEDH, y compensó el daño extrapatrimonial provocado por uno de los progenitores a la relación personal que tenía el otro con el hijo. De este modo, el Tribunal Supremo reconoce el daño moral en aquellos casos en que uno de los padres impide que el otro 
progenitor se relacione con su hijo menor. El bien jurídico protegido en este caso comprende el desarrollo de las relaciones personales entre el progenitor y el hijo, además del interés del menor $^{46}$.

En tanto, en nuestro país las demandas de indemnización por incumplimiento de deberes filiales no han prosperado ${ }^{47}$ por el hecho de que el principio de la reparación del daño en el Derecho de familia no ha sido reconocido y, por ende, no aplicado (OTÁROLA, 2016, p. 273; OTÁROLA, 2018, p. 810), aun cuando se avanza en garantizar los derechos de NNA, en especial el derecho a crecer en compañía de sus padres y reconocerlos como sujetos de derechos que deben ser oídos.

\section{CONCLUSIONES}

La transformación del ambiente familiar y de los roles que han asumido sus integrantes, en el contexto actual de la sociedad, ha puesto de manifiesto el importante papel que juegan en el bienestar de los niños y adolescentes instituciones como la familia y el Estado. Este último, por medio del establecimiento de un sistema que promueva su desarrollo y el ejercicio de sus derechos.

El Estado de Chile ha incorporado en su legislación el derecho a ser escuchado, el derecho a ser criado y educado por ambos padres; sin embargo, en el nivel de las prácticas concretas se presentan situaciones disímiles que han planteado la interrogante de si los tribunales de justicia han podido garantizar estos derechos. En efecto, se ha visto, por una parte, que los tribunales no siempre respetan el derecho de los niños y niñas a ser escuchados y a la debida consideración de su opinión en las decisiones que se plasman en la sentencia. Por otra, que los padres no comprenden que el ejercicio de la corresponsabilidad y la coparentalidad exige ponerse de acuerdo sobre cómo se van a ejercer los derechos-deberes que tocan a ambos tras la separación. Aunque en ese tránsito, los padres a veces deciden separar a los hijos de uno de los progenitores, incurriendo en la comisión del delito de sustracción de menores.

Todo lo anterior ha dado lugar -según se ha podido ver- a la necesidad de superar y mejorar las implicancias de no escucharlos, la forma en que se hace y la participación. Esto requiere de un mayor y profundo análisis sobre las condiciones del sistema y la competencia y formación de los operadores, a fin de facilitar el acceso de los niños a ver satisfecho su derecho, y que este no se torne solamente en la obligación de ser escuchados en una audiencia con el 
juez. También, exige incorporar en la decisión del juez las razones por las cuales consideró o no su opinión, habiendo evaluado si podía formarse un juicio. Por último, ha impuesto una mayor exigencia a nuestros jueces, pues en las situaciones en que los padres han roto y debido a esto no han podido ponerse de acuerdo sobre el tipo de relación que quieren tener, son ellos los que han debido encontrar una manera de vincularlos que garantice la continuidad de su función común como padres, asegurando el interés superior del niño y el derecho a relacionarse con ambos padres a fin de obtener el mejor bienestar posible. Cuestión que se ha logrado, en esta materia, mediante la aplicación de la Convención sobre los Derechos del Niño, el Convenio de La Haya sobre los Aspectos Civiles de la Sustracción Internacional de Menores, la absolución de los padres en el caso de la comisión del delito de sustracción de menores, porque se ha entendido que el bienestar subjetivo del NNA requiere de la crianza y educación de los hijos por ambos padres.

\section{NOTAS}

1: De acuerdo con el último Informe Anual de Justicia publicado por el Instituto Nacional de Estadísticas (INE) y realizado por ese organismo en conjunto con la Corporación Administrativa del Poder Judicial (CAPJ), durante 2018 ingresaron a los juzgados con competencia en familia 63.752 causas por divorcios, cifra que representa un aumento respecto a 2017, año en que se recibieron 59.635 causas. La cifra implica, a su vez, un 8,8\% del total de litigios ingresados en 2018 por materias relacionadas con la competencia de familia, entre las que se cuentan alimentos, impugnación de maternidad y paternidad, vulneración de derechos y patria potestad. Disponible en: https://www.ine.cl/estadisticas/sociales/seguridad-publica-y-justicia/justicia. Por otra parte, los ingresos y términos de "relación directa y regular" en tribunales con competencia en materia de familia: ingresos durante 2018, 2017 y 2016 (107.268, 107.636 y 113.299); terminadas en los mismos años (87.714, 89.607, 91.980). Corte de Apelaciones: ingresos $(1.584,1.446,1.316)$ y terminadas $(1.335,1.414$ y 1.278). Corte Suprema: ingresos (39, 27,39) y terminadas (34, 20 y 29). Boletín Estadístico Infancia. Dirección de Estudios Corte Suprema. Disponible en: http://decs.pjud.cl/download/boletin-estadistico-infancia/.

2: Según datos del Registro Civil, de los nacidos durante 2018 fueron inscritos 20.715 niños que solo fueron reconocidos por su madre, mientras que 3.640 menores fueron registrados solo por el padre. Las cifras de la institución también indican un aumento en los hijos nacidos fuera del matrimonio. Durante 2018 se inscribieron 241.420 niños, de los que 60.231 nacieron dentro del matrimonio. Por lo tanto, un $75 \%$ lo hizo fuera de este vínculo, que es cada vez menos contraído por los chilenos. El crecimiento en el número de niños nacidos fuera del matrimonio ha sido sostenido. En 2013 fue un 70,7\% y en 2008, un 64,6\% del total de menores que vinieron al mundo ese año. (El Desconcierto.cl, publicado el 15 de enero de 2019).

3: Un estudio de la University of British Columbia, de Canadá, revela que Chile es el país más feliz de Sudamérica, al ubicarse en el puesto número 20 del ranking World Happiness Report 2017. El Tercer Barómetro de la Felicidad, realizado por la Dirección de Estudios Sociales del Instituto de Sociología de la U. Católica (DESUC) y el Instituto de la Felicidad Coca-Cola, estudió y difundió el bienestar subjetivo de los chilenos: la importancia de nuestros vínculos. El estudio arrojó como conclusiones que la situación económica es motivo de infelicidad para los chilenos $(6,3)$ y que existe satisfacción con las relaciones familiares $(7,9)$, con la relación de pareja $(7,3)$ y con las amistades (7,5). Un 43\% de los encuestados asegura que "cualquiera puede ser feliz en Chile" y un 33\% piensa que "depende de la situación en que se nace". Magdalena Browne, de la Universidad Adolfo Ibáñez, asegura que la familia y las amistades figuran como factores positivos en la felicidad de los chilenos. Disponible en: https://escueladeadministracion.uc.cl/el-bienestar-subjetivo-de-los-chilenos-la-importancia-de-nuestrosvinculos/.

4: Informe Anual sobre Derechos Humanos en Chile, 2019. Universidad Diego Portales. Disponible en: http://www.derechoshumanos.udp.cl/derechoshumanos/images/InformeAnual/2019/Informe_DDHH_completo.p df. 


\footnotetext{
5: Observación General n. ${ }^{\circ}$ 12, p. 12. Disponible en: https://www.unicef.org/UNICEFObservacionesGeneralesDe 1ComiteDeLosDerechosDelNino-WEB.pdf.

${ }^{6}$ : Ley de Menores n. ${ }^{\circ} 16.618$, de 8 de marzo de 1967.

${ }^{7}$ : Ley n. ${ }^{\circ}$ 19.620, sobre Adopción de Menores, de 5 de agosto de 1999.

${ }^{8}$ : Ley n. ${ }^{\circ}$ 19.947, de Matrimonio Civil, de 17 de mayo de 2004.

${ }^{9}$ : Ley de Tribunales de Familia n. ${ }^{\circ} 19.968$, de 30 de agosto de 2020.

${ }^{10}$ : Ley n. 17.344 , sobre cambio de nombre, de 22 de septiembre de 1970.

11. Ley n. ${ }^{\circ} 21.067$, crea la Defensoría de los Derechos de la Niñez.

12. Con fecha 2 de abril de 2019 se publicó en el Diario Oficial el "Reglamento de la Ley n. ${ }^{\circ} 21.057$, que regula entrevistas grabadas en video y otras medidas de resguardo a menores de edad, víctimas de delitos sexuales", con el objetivo de dar cumplimiento a las obligaciones señaladas en el artículo 29 de la ley mencionada.

13. Corte Suprema, Rol n. ${ }^{\circ}$ 4528-19, de 11 de marzo de 2020. La madre recurre de la sentencia que da lugar a la petición de cuidado personal, sobre la base del argumento de que no se escuchó a la niña de tres años y no se nombró curador ad litem.
}

14: Resumen ejecutivo: Niños y niñas en tribunales de familia: el derecho a ser oído. Disponible en: http://www.boletinderecho.udp.cl/docs/resumenejecutivoudpunicef.pdf.

15. Bases técnicas específicas. Línea de acción diagnóstico. Modalidad diagnóstico ambulatorio. Disponible en: https://www.sename.cl/wsename./licitaciones/p5_17-03-2011/bases_tecnicas.pdf.

16. "En todos los asuntos de competencia de los juzgados de familia en que aparezcan involucrados intereses de niños, niñas, adolescentes, o incapaces, el juez deberá velar porque éstos se encuentren debidamente representados. El juez designará a un abogado perteneciente a la respectiva Corporación de Asistencia Judicial o a cualquier institución pública o privada que se dedique a la defensa, promoción o protección de sus derechos, en los casos en que carezcan de representante legal o cuando, por motivos fundados, el juez estime que sus intereses son independientes o contradictorios con los de aquél a quien corresponda legalmente su representación. La persona así designada será el curador ad litem [...]”. Artículo 19 de la Ley n. ${ }^{\circ}$ 19.968. Vid. cajmetro.cl/noticias/unidad-de-curaduria-ad-litem-de-la-oficina-de-familia-de-santiago/.

17: En España, el Tribunal Supremo se ha pronunciado en varias ocasiones respecto a la necesidad de ser oído el menor en los procedimientos que directamente le afectan; cuando la edad y madurez del menor hagan presumir que tiene suficiente juicio y, en todo caso, los mayores de 12 años habrán de ser oídos en los procedimientos judiciales en los que se resuelva sobre su guarda y custodia. El art. 92.6 del Código Civil español regula la audiencia de los menores por el juez, cuando tengan suficiente juicio y el juez lo estime necesario. El art. 770.1.4 de la Ley de Enjuiciamiento Civil (LEC) establece que "se les oirá, si tuvieren suficiente juicio y, en todo caso, si fueren mayores de 12 años".

El art. 777.5 de la LEC tiene una redacción similar a la del Código Civil, es decir, amplía las facultades del juez para oír o no al menor. En el artículo 9 de la Ley de Protección al Menor establece que "1. El menor tiene derecho a ser oído, tanto en el ámbito familiar como en cualquier procedimiento administrativo o judicial en que esté directamente implicado y que conduzca a una decisión que afecte a su esfera personal, familiar o social. En los procedimientos judiciales, las comparecencias del menor se realizarán de forma adecuada a su situación y al desarrollo evolutivo de éste, cuidando de preservar su intimidad. 2. Se garantizará que el menor pueda ejercitar este derecho por sí mismo o a través de la persona que designe para que le represente, cuando tenga suficiente juicio. No obstante, [...]”. La sentencia del Tribunal Supremo de 20.10.2014 dice: “La aparente contradicción entre el Código Civil y la Ley de Enjuiciamiento Civil viene a ser aclarada por la Ley del Menor y por el Convenio sobre Derechos del Niño, en el sentido de que cuando la edad y madurez del menor hagan presumir que tiene suficiente juicio y, en todo caso, los mayores de 12 años, habrán de ser oídos en los procedimientos judiciales en los que se resuelva sobre su guarda y custodia, sin que la parte pueda renunciar a la proposición de dicha prueba, debiendo acordarla, en su caso, el juez de oficio. En este mismo sentido la sentencia del Tribunal Constitucional de 6 de junio de 2005. Para que el juez o tribunal pueda decidir no practicar la audición, en aras al interés del menor, será preciso que lo resuelva de forma motivada. Sentencia del Tribunal Europeo de Derechos Humanos, Sección 3a, de fecha 11.10.2016 [...]. En lo que respecta particularmente al trámite de audiencia de las niñas por parte de un Tribunal, el TEDH ha estimado que sería ir demasiado lejos decir que los Tribunales internos están siempre obligados a oúr a un niño en audiencia cuando está en juego el derecho de visita de un padre que no ejerce la guarda. En efecto, esto depende de las circunstancias particulares de cada caso y teniendo debida cuenta de la edad y de la madurez del niño afectado (Sahin c. Alemania [GC], n. ${ }^{\circ}$ 30943/96, § 73, CEDH 2003-VIII. Observa, sin embargo, que en Derecho español (apartados 18 y 19 anteriores) en caso de procedimiento contencioso de divorcio, y si se estima necesario, los hijos menores, si son capaces de discernimiento, deben ser oídos por el Juez y, en todo caso, los menores con edades de 12 y más años. En cualquier caso, cuando el menor solicita ser oído, la denegación del trámite de audiencia deberá ser motivada. En función de lo expuesto procede acordar la nulidad de oficio de la sentencia recurrida, retrotrayendo las actuaciones al momento anterior a dictar sentencia para que antes de resolver sobre la guarda y custodia de los menores, se 
oiga a los mismos de forma adecuada a su situación y a su desarrollo evolutivo, cuidando de preservar su intimidad".

18: Artículo 3 de la Ley 16.

${ }^{19}$ : El artículo 229 fue sustituido por el número 8 del artículo 1 de la Ley $n^{\circ} 20.680$, publicada en el Diario Oficial el 21 de junio de 2013.

${ }^{20}$ : En este caso, una sentencia extranjera autoriza el ejercicio del régimen de relación directa y regular, en cuanto el padre puede sacar al niño del país durante los períodos de tiempo estipulados, prescindiendo de la autorización de la madre, quien tiene a su cargo el cuidado personal del niño. La Corte indica que la sentencia dictada contraviene la legislación nacional, en los términos que expone lo dispuesto en el artículo 49 de la Ley n. ${ }^{\circ} 16.618$. La Corte acoge el exequatur solicitado por el Tribunal de Apelación de París, Francia, entendiéndose que para los efectos de salidas del país del niño, deberá cumplirse con las formalidades dispuestas por la legislación nacional, particularmente con lo prescrito por el artículo 49 de la Ley n. ${ }^{\circ}$ 16.618. Corte Suprema, Rol n. ${ }^{\circ}$ 7.771-2019, de 28 de agosto de 2019.

${ }^{21}$ : Artículo $8^{\circ}$ n. ${ }^{\circ} 10$ de la Ley n. ${ }^{\circ} 19.968$.

${ }^{22}$ : En otro caso, la Corte Suprema revoca fallo que otorgaba permiso a la madre para salir del país con su hijo por el período de un año a partir del 15 de enero de 2014 con destino a Alanya, en Turquía. En la sentencia se sostiene que los jueces al otorgar la referida autorización, por el lapso de seis meses, vulneraron el interés superior del niño, porque perderá toda vinculación afectiva con su padre y la posibilidad de que este participe en la formación de su hijo; agrega que tampoco se acreditó el beneficio que el viaje le pudiera reportar; la existencia de la oferta de trabajo que se indica, su remuneración y las condiciones de vida para su hijo en el extranjero. Corte Suprema, Rol n. ${ }^{\circ} 8.820-2014$.

23. Se rechazó la solicitud de autorización de salida del país formulada por la madre, privando al hijo sin razones poderosas de la figura paterna, es decir, contraviniendo lo dispuesto en la Convención sobre los Derechos del Niño. La Corte Suprema rechaza autorización para la salida del país porque vulnera la estabilidad emocional presente del niño. La solicitante no entrega prueba sobre la oferta de trabajo en el extranjero que motiva la demanda y de las condiciones de vida que tendría el niño fuera del país. Plantea que se ha vulnerado el interés superior del niño y del derecho a mantener una relación directa y regular con el otro progenitor. Corte Suprema, Rol n. ${ }^{\circ} 8.820-2014$, de 28 de enero de 2015. En el mismo sentido, Corte Suprema, Rol n. ${ }^{\circ}$ 36593/2015, de 21 de abril de 2016. También, Corte Suprema, Rol n. ${ }^{\circ}$ 42642/2017, de 24 de abril de 2018; Corte Suprema, Rol n. ${ }^{\circ}$ 73900/2016, de 29 de diciembre de 2016; Corte Suprema, Rol n. ${ }^{\circ} 35522 / 2015$, de 18 de mayo de 2016.

24: Corte Suprema, Rol n. ${ }^{\circ} 27304-2014$, de 8 de junio de 2015.

${ }^{25}$ : Causa Rol n. ${ }^{\circ}$ 4.992-2019, de 30 de marzo de 2020.

26: Corte Suprema, Rol n. ${ }^{\circ} 35522 / 2015$, de 18 de mayo de 2016.

27: Corte Suprema, Rol n. ${ }^{\circ} 9.401-10$, de 14 de marzo de 2011.

28: Tribunal Constitucional, Rol n. ${ }^{\circ} 3928-17$, de 3 de noviembre de 2017.

${ }^{29}$ : Ley n..$^{\circ} 20.383$, de 24 de septiembre de 2009, introdujo una hipótesis especial en el artículo 49 bis de la Ley de Menores.

30: Corte Suprema, Rol n. ${ }^{\circ} 83503 / 2016$, de 29 de noviembre de 2016. También, Corte de Apelaciones de Talca, Rol n. ${ }^{\circ}$ 169/2010, de 9 de septiembre de 2010.

31: Los jueces cometieron falta o abuso al denegar la restitución del niño al extranjero y validar el actuar ilícito de la madre, quien pese a contar con una autorización para traerlo a Chile por un período determinado, lo mantuvo con ánimo de permanencia, sin consentimiento expreso del padre, infringiendo el derecho de custodia de este último, no obstante no concurrir ninguna de las situaciones descritas en el artículo 13 del Convenio de La Haya sobre los Aspectos Civiles de la Sustracción Internacional de Menores. Así, el padre siguió cumpliendo con su deber de otorgar alimentos, manifestando preocupación por su crianza y estado de salud, sin perjuicio de lo cual, una vez constatado que la madre no tenía planeado regresar a España, inició las gestiones administrativas necesarias para accionar judicialmente en Chile. Corte Suprema, Rol n. ${ }^{\circ}$ 5857-19, de 3 de septiembre de 2019.

${ }^{32}$ : Artículo 71 letra i) de la Ley n. ${ }^{\circ} 19.968$.

33: En Chile, Fiscalía Nacional. División de Estudios, Evaluación, Control y Desarrollo de la Gestión (DIVEST), 2015.

34: Según el análisis estadístico global de 2015, último año del que se disponen datos, el $73 \%$ de los sustractores son las madres; en el Informe de 2008 eran el 69\%, mientras que los padres constituyen el 24\% de los sustractores (el restante $3 \%$ corresponde a otros familiares, abuelos, o bien terceros). Añadiendo, además, que cuando la sustractora es la madre, en el $91 \%$ de los casos es la cuidadora principal del menor o menores. Esta preeminencia de la madre como sustractora debería ser un sonado toque de atención sobre el fondo, las causas o las motivaciones que impulsan la sustracción, así como sobre la muy insuficiente manera de abordar los casos de violencia doméstica por parte de los Estados y de la sociedad en general. Niguel Lowe and Victoria Stephens. Part I. A statistical analysis of applications made in 2015. Disponible en: https://assets.hcch.net/docs/d0b285f1-5f59-41a6ad83-8b5cf7a784ce.pdf.

35: Corte Suprema, Rol n. ${ }^{\circ}$ 3579/2011, de 25 de enero de 2013. 


\begin{abstract}
36: Corte Suprema, Rol n. ${ }^{\circ}$ 17976/2016 (Extradición Pasiva). No dio lugar a la extradición por sustracción de menores debido a que no concurre la referida exigencia tercera del artículo 449 del Código Procesal Penal; tanto por las dudas sobre la existencia de la doble incriminación y la aludida secuencia de ocurrencia de los hechos según la cual la conducta ocurrió cuando no existía disposición prohibitiva-, como por el imperativo de respetar las normas protectoras de derecho internacional relativas a los niños, niñas y adolescentes y aquellas que protegen a las mujeres -la requerida y sus hijas- contra la violencia.

37: Corte de Apelaciones de Valparaíso, Rol n. ${ }^{\circ}$ 2364/2019, de 5 de diciembre de 2019; Corte de Apelaciones de Valdivia, Rol n. ${ }^{\circ}$ 366/2012, de 6 de septiembre de 2012.

38: Corte Suprema, Rol n. ${ }^{\circ}$ 2467/2018, de 30 de mayo de 2019.

39: Entre los derechos del niño, la ONU (1989) recoge en el art. 11 de la Convención: “1. Los Estados Partes adoptarán medidas para luchar contra los traslados ilícitos de niños al extranjero y la retención ilícita de niños en el extranjero. 2. Para este fin, los Estados Partes promoverán la concertación de acuerdos bilaterales o multilaterales o la adhesión a acuerdos existentes".

40: El tribunal no dio lugar a la orden de depositar el total de la garantía -durante 10 años que la madre no trajo a los niños a Chile- por improcedente, y sin perjuicio de las acciones indemnizatorias que eventualmente pudieran interponerse; rechazó la solicitud de compensación (que es lo que atañe al recurso) por entender que se está pidiendo la modificación de la transacción de 2007 y sentencia de 7 de junio de 2010. Dio lugar, en cambio, a la petición primera, en el sentido de que se ordena a la madre cumplir con la relación directa y regular establecida por medio de la transacción de 2007 (29 de noviembre) y sentencia antes singularizada, bajo apercibimiento de aplicar multas y arresto en los términos establecidos en los artículos 48 y 66 de la Ley n. ${ }^{\circ} 16.618$ y 543 del Código de Procedimiento Civil. Corte Suprema, Rol n. ${ }^{\circ}$ 15.692/2019, de 4 de mayo de 2020.

41. Corte Suprema, Rol n. ${ }^{\circ} 16.650-2013$, de 16 de junio de 2014.

${ }^{42}$ : ¿Debe accederse a lo pedido por el padre y ordenar a la madre del hijo menor de ambos a restituir al país de origen al niño si esto acarrea terminar con su estilo de vida, redes y afectos que ha formado y desarrollado en el país en donde vive en la actualidad con su progenitora? Corte Suprema, Rol n. ${ }^{\circ} 2246 / 2009$, de 6 de julio de 2009. También, en Corte Suprema, Rol n. ${ }^{\circ} 8727 / 2012$, de 28 de febrero de 2013, y en Corte Suprema, Rol n. ${ }^{\circ}$ 16650/2013, de 16 de junio de 2014.

43. Corte Suprema, Rol n. ${ }^{\circ}$ 1715/11, de 30 de mayo de 2011; Corte Suprema, Rol n. ${ }^{\circ}$ 8727/2012, de 28 de febrero de 2013.

44: Corte de Apelaciones de Concepción, Rol n. ${ }^{\circ}$ 6544/2011, de 16 de agosto de 2011. También, Corte Suprema, Rol n. ${ }^{\circ} 1004 / 2005$, de 27 de abril de 2005.

45. Sentencia de 13.7.2000, Elsholz c. Alemania (TEDH 152), la cual condena a Alemania al pago de $€ 17.895,22$ (35.000 marcos); sentencia de 7.8.1996, Johansen c. Noruega; sentencia de 9.6.1998, Bronda c. Italia; sentencia de 11.7.2000, Ciliz c. Países Bajos; sentencia de 29.4.2003, Iglesias Gil c. España.

46. Sentencia del Tribunal Supremo, 1ª 30.6.2009 (RJ 5490).

47: Sentencia definitiva dictada por el $10^{\circ}$ Juzgado de Letras en lo Civil de Santiago, con fecha 27 de diciembre de 2013, en causa caratulada “Moller con Moller", Rol n. ${ }^{\circ}$ C-9243-2012. También, Corte Suprema, Rol n. ${ }^{\circ}$ 263/2010, de 13 de junio de 2012, y Corte de Apelaciones de Santiago, Rol n. ${ }^{\circ}$ 7738/ 2007, de 10 de octubre de 2009.
\end{abstract}

\title{
BIBLIOGRAFÍA
}

ACUÑA SAN MARTÍN, Marcela. "El principio de corresponsabilidad parental”, en Revista de Derecho de la Universidad Católica del Norte, vol. 20, n. ${ }^{\circ}$ 2, 2013. pp. 21-59.

BARCIA LEHMANN, Rodrigo. "La capacidad extrapatrimonial de los niños y adolescentes conforme a sus condiciones de madurez", en Revista Ius et Praxis, vol. 19, 2013. n. ${ }^{\circ}$, pp. 3 52 .

BOLAÑOS CARTUJO, Iñaki. "Custodia compartida y coparentalidad: una visión relacional”, en Revista de Psicopatología Clínica, Legal y Forense, vol. 15, 2015. pp. 57-72.

BUSTOS, Andrea. La representación judicial de los niños en los procedimientos proteccionales. Disponible en: http://derecho.udp.cl/wp- 
content/uploads/2019/12/20191218_La-representaci\%C3\%B3n-judicial-de-losni\%C3\%B1os-en-los-procedimientos-proteccionales.pdf.

CARRETA MUÑOZ, Francesco. "El derecho del niño a ser oído en la justicia de familia: la esencialidad del derecho versus la esencialidad del trámite de la audiencia confidencial", en Revista Chilena de Derecho, vol. 45, n. ${ }^{\circ} 2,2018^{a}$. pp. 407-426.

"Algunas precisiones adjetivas sobre el derecho del niño a ser oído, a propósito de un estudio empírico", en Revista de Derecho (Concepción), vol. 86, n. ${ }^{\circ} 243$, 2018b. pp. 93-119.

CASAS, Ferrán; ALFARO, Jaime; CASTELLÁ SARRIERA, Jorge et al. "El bienestar subjetivo en la infancia: Estudio de la comparabilidad de 3 escalas psicométricas en 4 países de habla latina", en Psicoperspectivas, vol. 14, n. ${ }^{\circ}$ 1, 2015. pp. 6-18.

CASTELLÁ SARRIERA, Jorge et al. "Bienestar subjetivo de los adolescentes: un estudio comparativo entre Argentina y Brasil", en Psychosocial Intervention, vol. 21, n. ${ }^{\circ} 3,2012$. pp. 273-280.

CUADRA, Haydée y FLORENZANO, Ramón. "El bienestar subjetivo: hacia una Psicología Positiva", en Revista de Psicología de la Universidad de Chile, vol. XII, n. ${ }^{\circ}$ 1, 2003. pp. 83-96.

DÍAZ, Guillermo. "El bienestar subjetivo: actualidad y perspectivas", en Revista Cubana de Medicina General Integral, vol. 17, n. ${ }^{\circ}$ 6, 2001. pp. 572-579.

ETCHEBERRY, Leonor. Autorización del menor para salir del país y sustracción internacional. Santiago de Chile, 2019, Colecciones Jurídicas de la Academia Judicial.

FARIÑA RIVERA, Francisca et al. "Clima familiar y coparentalidad en familias con ruptura de pareja", en Revista de Estudios e Investigación en Psicología y Educación, n. ${ }^{\circ 5,2017 . ~ p p . ~}$ 295-298.

GALLEGO HENAO, Adriana María. "Recuperación crítica de los conceptos de familia, dinámica familiar y sus características", en Revista Virtual Universidad Católica del Norte, n. ${ }^{\circ}$ 35, 2012. pp. 326-345.

GÓMEZ, Viviola et al. "Factores predictores de bienestar subjetivo en una muestra colombiana”, en Revista Latinoamericana de Psicología, vol. 39, n. ${ }^{\circ}$ 2, 2007. pp. 311-325.

GONZÁLEZ, Andrea. "Análisis crítico del rol del curador ad litem en la justicia de familia". Tesis para optar al grado de Magíster en Derecho, Universidad de Chile, 2017.

GUERRERO, Camila. El delito de sustracción de menores en Chile. Santiago de Chile, 2017, Ius Civile.

HERNÁNDEZ, Pedro. Psicología de la Educación. Corrientes actuales y teorías aplicadas. Ciudad de México, 1991, Editorial Trillas. 
" ¿La educación familiar puede configurar los moldes mentales o la inteligencia emocional de los hijos?", en International Journal of Developmental and Educational Psychology, vol. 1, n. ${ }^{\circ}$ 1, 2005. pp. 17-38.

LANSDOWN, Gerison. The evolving capacities of the child. Unicef, 2005.

LARRAÍN, Hernán (1994). Lecciones de Derecho Civil. Santiago de Chile, 1994, Editorial Jurídica de Chile.

LATHROP, Fabiola en PIZARRO WILSON, Carlos, Estudios de Derecho Civil: IV Jornadas de Derecho Civil. Santiago de Chile, 2009, Abeledo Perrot/Legal Publishing (La corresponsabilidad parental).

LLOBET RODRÍGUEZ, Javier. en KIELMANOVICH, Jorge L. y BENAVIDES SANTOS, Diego, Derecho Procesal de Familia. Editorial Jurídica Continental, 2008, Costa Rica. (El derecho del niño y adolescente a ser oído y a que se considere su opinión en los procesos judiciales)

LLOSADA-GISTAU, Joan; MONSERRAT, Carmen y CASAS, Ferrán. El bienestar subjetivo de los adolescentes tutelados en Cataluña. Barcelona, Dirección General d'Atenció a la Infància i l'Adolescència, 2016.

MATUS, Jean y RAMIREZ, María Cecilia. Lecciones de Derecho Penal chileno. $3^{\text {a }}$ edición, Santiago de Chile, 2014, Legal Publishing Reuters.

MOYANO DÍAZ, Emilio y RAMOS ALVARADO, Nadia. "Bienestar subjetivo: midiendo satisfacción vital, felicidad y salud en población chilena de la Región Maule", en Revista Universum, vol. 22, n. ${ }^{\circ}$ 2, 2007. pp. 177-193.

OTÁROLA, Yasna. Incumplimiento de los deberes matrimoniales y responsabilidad civil. Madrid, 2016, Reus.

en LLAMAS, Eugenio (ed.), Congreso Internacional de Derecho Civil octavo centenario de la Universidad de Salamanca. Valencia, 2018, Tirant lo Blanch, (La responsabilidad civil de los terceros derivada del incumplimiento del deber de fidelidad en el derecho chileno y comparado).

OYANEDEL, Juan Carlos; ALFARO, Jaime y MELLA, Camila. "Bienestar subjetivo y calidad de vida en la infancia en Chile", en Revista Latinoamericana de Ciencias Sociales, Niñez y Juventud, vol. 13, n. ${ }^{\circ} 1,2015$. pp. 313-327.

PÁEZ-MARTINEZ, Ruth Milena. “¿Des-víos de la familia en la formación de los hijos? Nuevos perfiles, funciones constantes", en Revista Latinoamericana de Ciencias Sociales, Niñez y Juventud, vol. 14, n. ${ }^{\circ} 1,2016$, pp. 261-272.

PALOMAR-LEVER, Joaquina. "Factores protectores y de riesgo que influyen en el bienestar subjetivo y económico de migrantes latinos en Boston, Estados Unidos", en Enseñanza e Investigación en Psicología, vol. 22, n. ${ }^{\circ}$ 1, 2017, pp. 86-102. 
ROBLEDO, Carola. "Análisis del derecho a ser oído del niño y a la participación en el nuevo derecho de familia". Tesis para optar al grado de Licenciado en Ciencias Jurídicas y Sociales de la Universidad de Chile, 2017.

RODRÍGUEZ, DOMINGUEZ, Carles et al. "Evaluación psicológica y legislación internacional: los traslados transfronterizos y sustracción de menores", en Papeles del Psicólogo, vol. 36, n. ${ }^{\circ}$ 1, 2015, pp. 46-53.

SALUM ALVARADO, Elena et al. "Derecho de los niños y las niñas a ser oídos en los tribunales de familia chilenos: la audiencia confidencial", en Revista Latinoamericana de Derechos Humanos, vol. 26, n. ${ }^{\circ}$ 2, 2015, pp. 53-79.

TRONCOSO, María y PUYOL, Carolina. "Derecho de niños, niñas y adolescentes a ser oídos en Tribunales de Familia: una aproximación psicojurídica", en Praxis. Revista de Psicología, año 16, n. $^{\circ} 25,2014$, pp. 89-105, I sem.

VALDIVIA, Carmen. "La familia: concepto, cambios y nuevos modelos", en La Revue du REDIF, vol. 1, 2008, pp. 15-22.

VARGAS PAVEZ, Macarena y CORREA CAMUS, Paula. "La voz de los niños en la justicia de familia de Chile", en Revista Ius et Praxis, vol. 17, n. ${ }^{\circ}$ 1, 2011, pp. 177-204.

VIVEROS CHAVARRÍA, Edison Francisco. "Roles, patriarcado y dinámica interna familiar: reflexiones útiles para Latinoamérica”, en Revista Virtual Universidad Católica del Norte, $\mathrm{n} .{ }^{\circ}$ 31, 2010.

Trabalho recebido em 01 de julho de 2020

Aceito em 05 de julho de 2021 